\title{
OS TERMOS RELATIVOS AO SEGMENTO GLBT (GAYS, LÉSBICAS, BISSEXUAIS E TRANSGÊNEROS) NO CONTEXTO DAS LINGUAGENS DOCUMENTÁRIAS
}

\author{
Claudio Roberto da Silva \\ Marilda Lopes Ginez de Lara
}

\begin{abstract}
Resumo
Este artigo sintetiza uma monografia de conclusão de curso que investiga a importância das palavras relativas à experiência de gays, lésbicas, bissexuais e transgêneros. A reflexão tem início com estudos sobre a formação da linguagem e de sua importância para a integração humana à cultura, diferenciando a linguagem natural da linguagem documentária através da compreensão sobre o processo de formação das LDs e do reconhecimento de seu poder ideológico. Na seqüência, dedica-se a recuperar o uso de termos relacionados a sexo e gênero no decorrer da história e à apresentação dos sistemas organizados por Dewey e Cutter (CDD e LCSH). Neste ponto, é feita uma análise sobre como esses sistemas sustentavam discursos produzidos pela autoridade científica, no primeiro caso, e, no segundo, pela imposição de padrões culturais relativos ao público majoritário e cujas características incapacitaram esses sistemas de atender a segmentos sociais mais específicos. Finalmente, a reflexão destaca as mudanças provocadas por sujeitos políticos que, aliados aos bibliotecários, ganharam espaço nos anos sessenta e que reconheceram a importância da guarda de materiais, de centros de documentação, como a necessidade de novas linguagens para atender ao público GLBT, dando origem a um novo campo de estudos sobre a análise da documentação.
\end{abstract}

\section{Palavras-chave}

Homossexualidade; Linguagens documentárias 


\section{INTRODUÇÃO}

Certa vez - corria o ano de 2002 nós, alunos do curso de Biblioteconomia e Documentação da ECA-USP, estávamos no horário do intervalo aguardando o início da segunda parte da aula de Lingüística e Documentação, quando uma colega contou uma história que chamou a atenção. Ela estagiava na Câmara Municipal e do local onde realizava suas atividades podia ouvir as sessões do plenário. Numa de suas audições aconteceu um episódio que despertou sua curiosidade. Uma bibliotecária fora convidada para ajudar ativistas dos grupos homossexuais. Na ocasião, a profissional se referiu ao termo técnico - homossexualismo - como ponto de partida para o debate. Aquém do significado dessa palavra entre os ativistas, ela abriu uma discussão, conhecida pelos grupos, segundo a qual o termo não poderia ser utilizado porque o sufixo "ismo" qualificava que a origem da palavra a associava à idéia de doença. Além disso, homossexual, no senso comum, era um termo atribuído ao gênero masculino, assim era preferível usar gays e lésbicas para dar visibilidade às mulheres, mas também havia a questão das travestis que não se reconheciam nessas duas palavras. Teve início um debate na Câmara que, provavelmente, não era do conhecimento daquela bibliotecária. Essa história foi ouvida e despertou nossa perplexidade, pois questionávamos: e se fossemos nós que estivéssemos naquela situação?

Esse artigo é a síntese de um trabalho de conclusão de curso que teve origem nessa história, visto a importância das palavras no contexto da linguagem e dos seus significados para as experiências de gays, lésbicas e travestis. Ele foi organizado com o objetivo de abranger os campos de estudos que reflitam sobre a complexidade da questão colocada àquela bibliotecária. A novidade do tema é visível e rica em possibilidades, pois compõe teias que articulam diversos campos do conhecimento, ligando os estudos das linguagens, da história, da importância do bibliotecário, das identidades de gênero e sexuais, num esforço de verificar os termos que se referem ao segmento GLBT (Gays, Lésbicas, Bissexuais e Transgêneros) no contexto das Linguagens Documentárias.

\section{A IMPORTÂNCIA DOS ESTUDOS DA LINGUAGEM SOBRE A SEDIMENTAÇÃO DA CULTURA}

No campo da reflexão contemporânea, parte dos estudos sobre a linguagem se liga à área da lingüística, particularmente ao corte reflexivo dado por Ferdinand Saussure. A perspectiva analítica a entende como um sistema convencionado de "signos" (GUIMARÃES, 2004). Esse sistema faz parte de um contexto sócio-cultural 
no qual os significados se tornam acessíveis aos sujeitos por causa do processo de aprendizagem. Nele, a língua surge como um elemento da integração humana ao contexto cultural (SCHAFF, 1974). Esse aprendizado, contudo, não garante uma univocidade de significados produzidos pelo discurso humano (PETRI, 1997). Essa consciência dos limites da objetividade da linguagem revela que o entendimento desses "signos" depende das relações construídas sobre eles dentro de um determinado contexto sócio-cultural (LOPES, 1975).

De acordo com o contexto em que a Linguagem Natural (LN) ocorre, pode-se gerar uma riqueza de compreensões, visto que a linguagem humana é caracterizada pela polissemia vocabular (CINTRA et al., 1994). Nesse sentido, coube a necessidade de se produzir uma linguagem que evitasse desentendimentos, a partir do tratamento das informações. É nesse processo que se encontra a definição de Linguagem Documentária. A LD é uma redução necessária do campo da LN. É um produto que se de define como uma linguagem artificial, assim chamada porque não resulta do processo evolutivo natural e necessita de regras explícitas para o seu uso (CINTRA et al, 1994).

Essa linguagem controlada depende da normalização das palavras para garantir sua univocidade nos Sistemas de Recupe- ração da Informação (SRI) (FOSKETT, 1977).

As LDs requerem uma sistematização da linguagem para evitar a dispersão de significados. Atualmente, devido à alta produtividade da informação, ocorre a necessidade da constante atualização das LDs. A compreensão desse último aspecto pontua a historicidade das LDs, onde os propósitos de garantir a univocidade das palavras perpetuam idéias que podem sucumbir com o tempo. O aparecimento de novas questões, do ponto de vista históricosocial, dá origem a novas compreensões das palavras ou até mesmo a novas palavras que tomam conta da linguagem. Uma vez que esse trabalho com o novo termo não seja realizado, há o risco das LDs se tornarem instrumentos datados.

Neste ponto, é preciso se referir a duas propostas que serão colocadas sob o foco da análise mais à frente: a de Melvil Dewey e a de Charles Cutter. A primeira teve origem em 1873, quando o autor criou um sistema de classificação, cujas características foram definidas como: simples, flexível e mnemônico. Esse sistema - pensado em termos filosóficos -, conhecido como Classificação Decimal Dewey (CDD), pressupunha que qualquer área do conhecimento poderia ser representada numericamente pela organização temática em classes sucessivas, onde cada classe possuiria uma subclasse mais específica. Em 
1895, a entidade precursora Federação Internacional de Documentação (FID) chegou a um acordo com Melvil Dewey, adotando a classificação decimal como base para um índice internacional de assuntos.

Esse acordo deu origem a Classificação Decimal Universal (CDU) (LENTINO, 1971). Por outro lado, ocorreu o desenvolvimento de outro sistema - em termos mais utilitários - que também se tornou conhecido: a Library of Congress (LC). Em princípio, Melvil Dewey foi consultado sobre a possibilidade da CDD, se fosse necessário, ser modificada para se adequar à coleção da LC, como não concordou, Charles Cutter ao aceitar teve seu sistema de classificação expansiva adotado pela LC (KAULA, 2004). Essa característica fez com que esse sistema alfa-numérico continue em expansão. Essa tarefa é feita pelos classificadores da LC, os quais se encarregam de atualizar a LCSH (Library of Congress Subject Headings), uma lista de cabeçalho de assuntos que apropria novos temas ao sistema à medida que aparecem.

No começo do século XXI, a sistematização presente nessas propostas levantou problemas relacionados ao poder que se escondia sob a aura do saber e que as legitimavam por meio dessas LDs. Essas Linguagens se referiam às formas de sistematização nas quais a representação temática sofria restrições, tornando os termos - que as estruturavam - aceitos insti- tucionalmente como verdadeiros ou autorizados.

É preciso compreender o poder que se expressava por meio dessas linguagens, cuja constituição se deveu a fatores sócio-culturais - que justificavam a reprodução de processos ideológicos - a partir dos quais as palavras adquiriam significados que ninguém ousava questionar. É sob esse aspecto que a linguagem se tornava ideológica.

A partir dela o indivíduo constitui a crença de que possui o domínio da linguagem, e, também, a ilusão de que o sentido prévio das palavras já existe (BACCEGA, 1995).

Essas características revelam que a ideologia pode ser compreendida como efeito da ligação entre o ser humano e a linguagem, pois ela não se manifesta para a consciência e permanece por meio da recusa de reflexão do indivíduo (CHAUÍ, 1980). Dito de outro modo, a linguagem não é vista como resultado de processos sócio-culturais. Os estudos históricos dos termos relacionados a segmentos sociais específicos podem aventar questões como: até que ponto e como os membros dos grupos "minoritários" - pertencentes à comunidade GLBT - foram, ou não, representados pelas palavras que veicularam no decorrer do tempo? Ou, como os significados presentes nessas palavras se constituíam dentro do sistema de relações sociais, 
políticas e culturais? Essa preocupação reconhece o caráter dinâmico e relativo das palavras, assim como dos significados que foram construídos em relação à sistematização das linguagens.

\section{UMA HISTÓRIA DOS TERMOS SOBRE SEXO E GÊNERO}

Os estudos históricos contribuem para a avaliação sobre as diferentes palavras que circularam em relação à diversidade sexual. Na Antiguidade, os homens a reconheceram, nomearam e construíram explicações que sustentavam suas instituições.

O Antigo Testamento, por exemplo, conta a história de um pequeno povo, os judeus, que convivia com os rigores do deserto. Nesse ambiente, desperdiçar o sêmen implicava em diminuir suas possibilidades de existência. A religião, então, traçou um código sagrado com regras acerca do corpo, das vestimentas e dos relacionamentos afetivos que deveriam ser obedecidos pelo povo judeu (SPENCER, 1996).

Entre os gregos, por outro lado, é mais adequado falarmos em relações amorosas (SERGENT, 1984) para as quais havia uma hierarquia de valorização. A pederastia era a mais valorizada, tratava-se de uma união baseada na idéia de que o erasta (amante) treinasse seu amado (païs: efebo) nos princípios da sabedoria, da hon- ra e da valentia (HUNT, 1974). Os gregos sentiam-se fascinados pelas mulheres que vendiam seus favores (SALLES, 1987), mas elas eram consideradas inferiores aos referidos princípios.

Nessa sociedade, o amor não se encontrava nos lares, sendo que o casamento era um dever do cidadão com a polis que padecia de grande desprestígio (HUNT, 1974).

No tocante à civilização romana, diferente da grega, a motivação era mais ligada à satisfação física e à idéia de penetração. Para os romanos, a virilidade referiase com a expansão do seu império e a subjugação dos conquistados (ARIÈS, 1987). Temia-se que as mulheres romanas, que tinham mais autonomia que as gregas, ao manterem relações afetivas, apenas entre elas, pudessem tomar as posições de comando dos homens. Ao recuperarmos os modelos greco-romanos, é preciso ressaltar a idéia de que o sujeito dirigia suas investidas respeitando as leis e os costumes (FOUCAULT, 1988). Esse controle passava pela reflexão que o cidadão da Antiguidade Clássica deveria fazer, pois ele teria que possuir sabedoria para comandar seus prazeres e preservar seu status.

A transformação dos valores culturais - entre o período antigo e o medieval - ocorre com o declínio do Império Romano (RICHARDS, 1993). Nessa fase, a ascen- 
são do cristianismo realizou conquistas em favor da castidade que deslocaram os padrões culturais greco-romanos. O controle que o sujeito tinha sobre os próprios prazeres perdeu espaço para o controle moral e legal exercido pelos outros (HUNT, 1974). Esse processo dará origem à categorização religiosa das relações que não tinham por fim a procriação (chamadas de "contra naturam" ou contra a natureza), estabelecendo a nominação das práticas como sodomia e das pessoas como sodomitas, termos originados do relato bíblico sobre a destruição das cidades de Sodoma e Gomorra.

Nessa fase, iniciou-se o caminho em direção à institucionalização da monogamia e à indissolubilidade do casamento, a qual passou a formular uma jurisdição que invadiu o leito dos casados para o exercício da sexualidade. Nela, o intercurso sexual só estaria livre do pecado se fosse feito sem a participação do prazer e para fins ligados à procriação. Essas proposições se tornaram lei após a divisão do Império Romano, quando a parte do Oriente adotou o cristianismo como religião oficial (BOSWELL, 1985).

Com a formação das monarquias nacionais e a ascensão do catolicismo, as autoridades da Igreja e dos Estados deram início à supressão da individualidade em favor da comunidade. A sodomia começou a ser tratada como uma ofensa à socieda- de, sendo punida em nome da manutenção da ordem. Uma das expressões mais francas do controle da Igreja Católica - e que atinge o exercício da sexualidade - foi a instituição dos tribunais da Inquisição, criados para impedir os desvios da fé (BELLINE, 1987).

Em meados do século XIII, os dispositivos da repressão sobre o corpo e o prazer tinham se estabelecido, funcionando como instrumentos de perseguição para aperfeiçoar o controle sobre o indivíduo, a fim de manter a uniformidade de princípios religiosos, políticos e sociais. No final do período medieval, esses instrumentos de controle se sofisticaram, começando a deixar o campo da fé para ocupar o campo da razão.

Para compreendermos a transição que se constituiu entre o período moderno até a época atual, é preciso recuperar a tradição da Igreja Católica em manter a sodomia relegada à categoria de pecado nefando, ou aquele não deve sequer ser mencionado (BAUDRY; DANIEL, 1977). Esse silêncio dará lugar à proliferação de palavras que farão a catalogação dos pecados contra a natureza. Com o advento da Idade Contemporânea, a projeção dos valores cristãos foi preservada - em relação à díade sexo-reprodução - por meio do pensamento científico que, por sua vez, fará a catalogação dos "desvios sexuais" (FOUCAULT, 1988). Nesse contexto sur- 
gem as identidades sexuais, tornando-se possível falar de um individuo sobre o qual se pode exercer controle: o homossexual. Durante o século XIX, a medicina, a jurisprudência e a literatura produziram discursos que permitiram mais avanços sobre 0 controle da sexualidade. O saber médico era perpassado pela teoria de que o funcionamento da sociedade dependia de um organismo composto por indivíduos saudáveis (SHOWALTER, 1993). Até a metade do século $X X$, o espaço das instituições médico-jurídicas transformará corpos em espécimes doentes que serão aprisionadas em sanatórios e hospitais. Neste contexto, os homossexuais serão apresentados como promotores da degenerescência social (GUIMARÃES, 1994). Com a ascensão dos regimes nazistas e fascistas a perseguição aos homossexuais se tornou implacável, continuando após a origem do antagonismo político-ideológico entre EUA e URSS, no qual a homossexualidade era vista ou como uma "fraqueza moral" pelos americanos, sujeita a chantagem pelos comunistas, ou como uma "degenerescência burguesa" do capitalismo pelos soviéticos.

Em 1948, a discussão tomou nova dimensão. O Relatório Kinsey era publicado e seu autor reconhecia que a função sexual e a função reprodutiva estavam separadas. Kinsey demoliu estereótipos construídos sobre a sexualidade. Uma das alegações teóricas do autor era que o "ho- mossexualismo" não existia, não era uma síndrome clínica e nem uma degenerescência social (ROBINSON, 1977). Com esses argumentos Kinsey deu início a reflexões mais tolerantes sobre a homossexualidade.

Durante os anos sessenta, tanto na Europa quanto nos Estados Unidos, os movimentos de caráter libertário abriram caminho aos de luta por direitos civis de mulheres, negros e homossexuais. Os discursos conclamavam uma transformação visceral dos costumes e das instituições sociais (COELHO, 1987). Essa defesa alcançou a mídia e a academia. Um dos ecos ocorreu em 1973, quando a Associação Americana de Psiquiatria retirou a homossexualidade da lista de doenças mentais (MONEY, 1988).

A mídia começou a dar notícias sobre a AIDS antes dessas mudanças completarem uma década. Isso provocou um refluxo: a questão homossexual passou a ser associada ao perigo de propagação do vírus HIV (POLLAK, 1990). A organização dos ativistas foi a forma de reação adotada para fazer frente à AIDS. O segmento gay viu-se obrigado a enfrentar a epidemia, empreendendo ações educativas, nas quais - ao mesmo tempo em que aprendia -, ensinava que as práticas sexuais tinham de ser planejadas. Teve de realizar ações de assistência às vítimas e aprender a conviver com a morte. 
No final dos anos oitenta e início dos anos noventa, o perfil social da AIDS começou a mudar, atingindo outros segmentos. Contudo, a luta contra a epidemia evidenciou o debate sobre a diversidade de práticas sexuais (PARKER, 1991). No verão de 1990, essa necessidade mostrou a Queer Nation, um movimento que possuía participantes que não priorizavam a definição por meio de identidades, como gay ou lésbica, e se interessavam apenas por debater a questão da diversidade de práticas sexuais (PARKER, 2002). Essa forma de ativismo levou a inclusão de bissexuais e transgêneros, esboçando a importância das palavras em abranger uma diversidade obscurecida pelo termo homossexual.

No período que corresponde à virada do século $X X$, as gerações contemporâneas presenciam manifestações de massa, em nome da diversidade sexual, ao redor do mundo: como as celebrações ligadas ao dia 28 de junho: "Dia do Orgulho GLBT" (nome utilizado pela Parada do Orgulho de São Paulo, a maior do planeta).

\section{O TRATAMENTO DA SEXUALIDADE} NAS LINGUAGENS DOCUMENTÁRIAS NO PERÍODO MODERNO

Para compreender o tratamento dado à sexualidade pelas LDs, é fundamental retomar Foskett (1971). O autor sugere que os sistemas de classificação refletem a estrutura da sociedade na qual foram cria- dos. O reconhecimento desse aspecto é importante, pois as linguagens propostas por Dewey e Cutter possuem normas que se organizaram a partir da identidade do homem, branco, burguês, heterossexual, ocidental, cristão (OLSON, 2002). Dewey as incorpora ao aceitar a autoridade científica como critério para a organização da CDD, e Cutter ao aceitar os termos de domínio público (estratégia que dará origem a LCSH) também como critério de sistematização.

Esta é a chave para se observar como os sistemas propostos pelos autores acabaram por cooptar uma heterogeneidade que é homogeneizada nessas LDs.

O objetivo dos autores era montar vocabulários universais, mas não conseguiram atingi-lo. Em parte, devido aos limites ligados às suas propostas: Dewey ao empregar a hierarquia por meio do modelo de classificação numérica por classes e subclasses; e Cutter ao privilegiar uma estrutura conectiva na forma dicionário-catálogo, propondo um conjunto inteiro e fechado de relações entre nomes. Nesses modelos, os termos são representados a partir da uniformidade das linguagens e o resultado é a marginalização e a exclusão de tópicos que não se ajustavam: ou devido aos cânones eleitos pelos especialistas para descrevê-los na CDD; ou em razão de um uso público que não os valorizava no contexto cotidiano na LCSH (OLSON, 2002). 
Os sistemas de classificação, almejados por Dewey e Cutter, não eram neutros e estavam longe de serem ferramentas objetivas, pois reforçavam perspectivas ideológicas. As suas obras carregam um legado exposto nos catálogos das unidades de informação. A aplicação dos princípios propostos fez com que os bibliotecários reiterassem os discursos institucionalizados por essas LDs. O processo de sistematização das informações realizado pelos indexadores, criava situações propícias ao emprego das identidades privilegiadas. Essa imposição acabou por marginalizar e excluir as "outras" identidades que não eram as de homens, brancos, ocidentais, burgueses, heterossexuais e cristãos. Essa parcialidade ocorria em razão da própria possibilidade de representação apresentada pelas LDs - a partir de oposições binárias -, onde a relação hierárquica entre dois conceitos tornava um dominante e visível e o outro subordinado e invisível (OLSON, 2002).

A autora Hope Olson (2002) denomina esse processo de "nomear", na perspectiva de entendê-lo como uma forma de poder ligado ao controle da representação dos conteúdos e do acesso aos assuntos. $\mathrm{O}$ ato de "nomear", segundo a autora, está na base da construção dos SRIs que, ao imporem a uniformidade, estabelecem uma "linguagem universal arbitrária, despótica, tirânica e violenta" (OLSON, 2002, p. 4). Nessas concepções de representação te- mática, as possibilidades propostas por Dewey e Cutter acabaram por definir inclusões e exclusões de determinados segmentos sociais.

Entre os setores que mais contestaram a legitimidade dessas linguagens, estavam as feministas que se referiam ao sexismo presente na representação de materiais sobre e para mulheres. Como resultado dessas críticas, foram empreendidas reflexões com o objetivo de denunciar a parcialidade desses sistemas de representação. O aparecimento dessa problemática colocou questões ao trabalho com as LDs tradicionais, as quais se tentava solucionar, mas a resolução nunca alcançou um nível satisfatório (OLSON, 2002). Essa revisão abriu espaço para o reconhecimento dos limites dessas linguagens.

Desde as implementações das propostas de Dewey e de Cutter, a classificação de publicações sobre homossexualidade encontra dificuldades. No caso da CDD, como a organização é feita por áreas do conhecimento, o material pode ser armazenado em locais diferentes, podendo gerar um efeito denominado "diáspora", no qual as informações são dispostas em lugares separados. Por outro lado, também há o fenômeno da guetorização, visto que o uso das tabelas, ao fazer a classificação, estabelece marcas - por meio de termos como gays ou lésbicas, por exemplo -, que sedimentam os guetos e privilegiam a re- 
presentação de um aspecto identitário em detrimento dos "outros" (OLSON, 2002).

A LSCH também possui aspectos que se refletem no tratamento das informações sobre a homossexualidade. A assimilação das mudanças em relação aos termos de uso público é lenta. A estrutura criada para estabelecer as referências os põe sob o cabeçalho "minorias" que fica no centro da hierarquia. Esse termo - que pode ser visto como categoria sociológica e política -, ao ser veiculado pela LCSH traz em sua definição aspectos que fazem a representação dos grupos não-dominantes. Há também a palavra "discriminação", utilizada como termo relacionado que reitera questões sócio-culturais referentes à opressão e à estigmatização dos grupos minoritários (OLSON, 2002).

As LDs tradicionais, portanto, não são ferramentas neutras. Elas refletem valores dominantes. Os seus sistemas de representação não conseguem abranger a universalidade, seja por meio dos números de classificação da CDD, ou do cabeçalho de assunto da LCSH, que não traduzem satisfatoriamente conceitos referentes à homossexualidade. Na verdade, essas ferramentas, presumidamente, propostas como linguagens universais, colocam a diversidade na marginalidade dos sistemas de tratamento temático. Os termos que aparecem nessas LDs não fornecem representações refinadas para satisfazer as necessi- dades de informação do segmento composto por gays, lésbicas, bissexuais e transgêneros. Neste ponto, os estudos mais recentes, ligados às necessidades de informação de segmentos específicos, anunciam um caminho diferente, no qual seja possível aos "outros" dessas linguagens construírem as suas próprias representações.

\section{DESAFIO DAS MUDANÇAS PROVOCADAS PELA EXPLOSÃO DA INFORMAÇÃO}

A partir dos anos cinqüenta, o conceito de LDs - que na reflexão de Dewey e Cutter podiam abarcar a universalidade -, começou a ser alterado. Surgem novas propostas de classificação, entre elas os thesauri. Essas linguagens passaram a classificar a informação de campos cada vez mais específicos, caminhando no sentido oposto à universalidade de sistemas binários e hierarquizados, como os presentes nas linguagens da CDD e da LCSH (OLSON, 2002).

No decorrer dos anos sessenta, novos sujeitos - ligados ao debate sobre relações de gênero, raça/etnia, orientação sexual - estavam dando uma nova dimensão às lutas políticas. Naquele momento, a homossexualidade se tornou uma instância de debate dos próprios homossexuais. Esse contexto se desdobrou na criação de arquivos e bibliotecas voltados para esse 
público. A reviravolta política refletiu-se na missão desses centros de documentação, na atuação dos profissionais que neles trabalhavam e nas ferramentas técnicas de classificação, sistematizando uma linguagem que criou termos adotados orgulhosamente como símbolo de afirmação social e política pelo segmento GLBT.

Antes, porém, é preciso recordar um dos mais antigos centros de documentação que continha uma enorme divisão de materiais sobre homossexualidade e que foi destruído com a ascensão do nazismo: o Instituto de Ciência Sexual de Berlim, comandado por Magnus Hirshfeld (LAURITSEN; THORSTAD, 1974). Atualmente, os centros de documentação que atendem ao segmento gay e lésbico ainda são poucos em termo numéricos - calculase que haja por volta de 110 entidades espalhadas pelo planeta - e nem todos são mantidos e alojados satisfatoriamente (WARREN, 2004).

Boa parte das entidades não tem apoio econômico e sobrevive do trabalho de voluntários (LUKENBILL, 2002). Apesar disso, essas coleções são necessárias para que as gerações de gays e lésbicas que se sucedem e se reconhecem por meio dessas categorias - possam se reunir pelos elos representados por livros, revistas, fotografias, diários pessoais, entre tantas coisas, relacionados à temática (KNIFFEL, 1993).
Por outro lado, é importante destacar que os bibliotecários e os arquivistas estiveram na vanguarda do movimento ligado ao segmento GLBT, trabalhando para coletar e preservar materiais relevantes a sua história.

A movimentação dos anos sessenta despertou os bibliotecários norte-americanos - tanto em nível pessoal quanto em nível profissional - a dedicar-se às causas ligadas à transformação da sociedade. A Social Responsability Round Table (SRRT) surgiu no auge das revoluções sociais dessa época. Em 1970, a SRRT reivindicou junto à American Librarian Association (ALA) a formação da primeira organização profissional de gays e lésbicas do mundo, fundando a: Task Force on Gay Liberation.

Desde então, a organização incluiu outras identidades sexuais, assumindo o nome de Gay, Lesbian, Bisexual and Trangenders Task Force (GLBTTF). A trajetória desse grupo é marcada pelos esforços em refletir e trabalhar sobre as necessidades de informação do segmento GLBT (SEIDEL, 1999).

A partir desse momento, os bibliotecários ligados a essa perspectiva se colocaram na vanguarda da criação de linguagens que possibilitassem um tratamento temático diferente, porém não menos ideológica. Este grupo, ao refletir sobre uma linguagem sistemática que fizesse a representação dos assuntos GLBT, dividiu-se 
entre a possibilidade de continuar utilizando as LDs tradicionais, ou de adequá-las às necessidades específicas desse segmento, e a possibilidade de partir para a elaboração de tesauros que atendessem às demandas emergentes com o movimento homossexual e, posteriormente, com a fragmentação da identidade homossexual sob a sigla GLBT: gays, lésbicas, bissexuais e transgêneros (OLSON, 2002).

Foram essas questões que conduziram a reflexão sobre os sistemas de classificação. Esses sistemas passaram por uma revolução epistemológica no final dos anos noventa (CAMPBELL, 2000). Essas novidades geraram um número considerável de pesquisas no campo de estudos sobre a informação, tanto dos profissionais (ao criar e implementar "ferramentas" de acesso mais eficientes), quanto dos teóricos (ao tentar articular os fundamentos conceituais sobre os quais estas "ferramentas" se apóiam).

Esse fato teve impacto na produção de vocabulários controlados. A diferença se manifestou por meio das novas regras que se referiam à organização de linguagens elaboradas, agora, a partir de múltiplos "centros". Neles, os termos, conceitos e categorias foram adotados para refletir as necessidades de informação que atendiam as demandas específicas de diferentes grupos. A partir dessa proposta foram projetados sistemas com o objetivo de classifi- car a informação utilizada pelo público GLBT.

As teorias, particularmente, entraram num período altamente politizado, pois não ostentavam mais a crença de que um esquema de classificação pudesse ser culturalmente neutro e, portanto, aplicável universalmente, mas se reconhecia a sua relatividade. Este debate revelou que o tratamento da informação, mesmo que fosse feito a partir das "margens", também poderia produzir outras formas de "uniformidade".

Para os pesquisadores ficou claro que o saber e o poder ainda se entrelaçavam no significado que circulava com as informações sobre o segmento GLBT. Tal exigência sinalizou para o debate de que o bibliotecário não realizava tarefas meramente técnicas, mas que o tratamento da informação o põe na posição de refletir sobre o posicionamento social e político dos termos - que contesta ou reitera - ao colocá-los em circulação por meio das Linguagens Documentárias.

\section{CONSIDERAÇÕES FINAIS}

É inevitável e necessário concluir essa reflexão comparando a presença desse debate entre os bibliotecários norteamericanos e os bibliotecários brasileiros. A pesquisa nas bases de dados revela que esta discussão, quando comparadas as 
duas realidades, está por ser iniciada aqui. Uma explicação para essa carência de títulos na área de documentação no Brasil pode ser atribuída à atualidade do assunto.

O contato com a literatura norteamericana foi muito importante. Após o início das leituras, o fato de os norteamericanos estarem avançados nesse debate não pareceu estranho, visto que a primeira associação profissional declaradamente gay do mundo (ALA's Gay, Lesbian, Bisexual and Transgendered Task Force) constitui-se nesse país e seus participantes começaram a produzir uma série de reflexões que colocou em evidência a relação da Biblioteconomia com esta questão.

As bibliotecas brasileiras, grosso modo, ainda utilizam as LDs tradicionais para alimentar seus SRIs, secundando todos os problemas que podemos observar no decorrer dessa reflexão. Entretanto, já há inovações ligadas ao atendimento das necessidades de informação específicas, e a existência de centros de informação voltados ao segmento composto por gays, lésbicas, bissexuais e transgêneros brasileiros.

O emprego dessas palavras provenientes do hemisfério norte renova um dilema proposto por Oswald de Andrade e que atualmente pode ser dirigido aos bibliotecários do hemisfério sul: trata-se do "Tupi or not Tupi" (eis a questão). Diante dele, é preciso seguir a sugestão antropofágica do autor que nos aconselha a devorar as palavras para digeri-las, transformá-las e depois adaptá-las ao contexto cultural brasileiro.

\section{REFERÊNCIAS}

ARIĖS, P.; BÉJIN, A. (Orgs.). Sexualidades ocidentais. São Paulo: Brasiliense, 1987.

BACCEGA, Maria Aparecida. Palavra e discurso: História e Literatura. São Paulo: Ática, 1995.

BAUDRY, A.; DANIEL, M. Os homossexuais. Rio de Janeiro: Artenova, 1977.

BELLINI, Lígia. A coisa obscura: mulher sodomia e Inquisição no Brasil Colonial. São Paulo: Brasiliense, 1987.

BOSWELL, John. Christianisme, tolerance sociale et homosexualité: les homosexuals en Europe Occidentale des débuts de l'ère chrétienne au XIVe. Siècle. France: Gallimard, 1985.

CAMPBELL, G. Queer theory and the creation of contextual subject access tools for gay and lesbian communities. Knowledge Organization, v.27, n.3, p.122-31, 2000.

CHAUI, Marilena. O que é ideologia. São Paulo: Brasiliense, 1980.

CINTRA, Anna Maria Marques et al. Para entender as linguagens documentárias. São Paulo: Polis, 1994.

COELHO, C. N. P. Os movimentos libertários em questão. Petrópolis: Vozes, 1987.

FOSKETT, A. C. Mysoginists All: a study in critical classification. Library Resources \& Technical Services, v.15, n.2, p.117-21, 1971.

. The subject approach to information. London: Clive Bingley, 1977. 
FOUCAULT, Michel. História da sexualidade II: o uso dos prazeres. Rio de Janeiro: Graal, 1988.

GUIMARÃES, Celeste Zenha. Homossexualismo: mitologias científicas. Campinas: UNICAMP, 1994. Tese (Doutorado em História) Programa de Pós-Graduação em História, IFCH - UNICAMP, 1994.

GUIMARÃES, Eduardo. Os estudos sobre linguagens: uma história das idéias. Disponível em:

<http://www.comciencia.br/reportagens/ling uagem/ling14.htm>. Acesso em: 28 de jun. 2004.

HUNT, Morton M. Dilema na Grécia: A invenção do Amor. In: Sexo: teoria e prática. São Paulo: IBRASA, 1974.

KAULA, Prithvi N. Repensando os conceitos no estudo da classificação. Disponível em:

<http://www.conexaorio.com/biti/kaula/>. Acesso em: 6 nov. 2004.

KNIFFEL, L. You gotta have Gerber-Hart: a gay and lesbian library for the Midwest. American Libraries, v.24, n.10, p.958-959, 1993.

LAURITSEN, J.; THORSTAD, D. The Early Homosexual Rights Movement (18641935). New York: Times Change Press, 1974.

LENTINO, Noêmia. Guia teórico, prático e comparado dos principais sistemas de classificação bibliográfica. São Paulo: Polígono, 1971.

LOPES, E. Fundamentos da Lingüística contemporânea. São Paulo: Cultrix, 1975.

LUKENBILL, W. B. Modern gay and lesbian libraries and archives in North America: a study in community identity and affirmation. Library Management, v.23, n.1/2, p.93-100, 2002.
MONEY, John. Gay, Straight and In-

Between: the sexology of erotic orientation. New York: Oxford University Press, 1988.

OLSON, Hope A. The Power to Name: locating the limits of subject representation in libraries. Dordrecht/Boston /London: Kluwer Academic Publishers, 2002.

PARKER, Richard G. Corpos, prazeres e paixões. São Paulo: Best Seller, 1991.

- Abaixo do Equador: culturas do desejo, homossexualidade masculina e comunidade gay no Brasil. Rio de Janeiro: Record, 2002.

PETRI, Dino. Sociolingüística: os níveis de fala. São Paulo: Edusp, 1997.

POLLAK, Michael. Os homossexuais e a AIDS. São Paulo: Estação Liberdade, 1990.

RICHARDS, Jeffrey. Sexo, desvio e danação: as minorias na Idade Média. Rio de Janeiro: Jorge Zahar, 1993.

ROBINSON, Paul. A modernização do sexo: ensaios sobre Ellis, Kinsey, Máster \& Johnson. Rio de Janeiro: Civilização Brasileira, 1977.

SALLES, Catherine. Nos submundos da Antigüidade: les bas-fonds de l'antiquité. São Paulo: Brasiliense, 1987.

SCHAFF, Adam. Linguagem e conhecimento. Coimbra: Almedina, 1974.

SEIDEL, Heike. The Invisibles: lesbian women as library users. Progressive Librarian, v.14, p.34-43, 1998.

SERGENT, B. L'homosexualité dans la mythologie grecque. Paris: Payot, 1984.

SHOWALTER, Elaine. Anarquia sexual: sexo e cultura no fin de siècle. Rio de Janeiro: Rocco, 1993.

SPENCER, Colin. Homossexualidade: uma história. Rio de Janeiro: Record, 1996. 
WARREN, Patricia Nell. How real is our sense of "history"? Disponível em: $<$ http://www.rslevinson.com/gaylesissues/fe atures/collect/guest/blwarren.htm> Acesso em: 20 ago. 2004.

\section{Claudio Roberto da Silva \\ Bacharel em Biblioteconomia e Documen- tação (ECA-USP) \\ Mestre em História Social (FFLCH-USP) Doutorando em Educação (FE-USP) crsillva@uol.com.br}

\section{Marilda Lopes Ginez de Lara Profa $^{a}$. do Dept ${ }^{\circ}$ de Biblioteconomia e Do- cumentação da ECA-USP \\ larama@usp.br}

\section{Title}

The terms related to the GLBT (Gays, Lesbians, Bisexuals and Transgenders) segment in the Documentary Languages context

\section{Abstract}

This article synthesizes a final course monograph that searched about the importance of the words related to the gays, lesbians, bisexuals and trangenders experience. This reflection begins with studies about the language formation and its importance to the human integration to the culture, discerning the natural language from the documentary language through the comprehension about the process of LDs formation and the recognition of its ideological power. After this, the article dedicates to recover the use of terms related to sex and gender during the course of history and to present the systems organized by Dewey and Cutter (CDD and LCSH). At this point, it makes an analysis about how these systems sustained the discourses produced by scientific authorities, in the first case, and, in the second case, by the imposition of cultural standards related to the major public, whose characteristics disabled these systems to attend to more specific social segments. Finally, this reflection emphasizes the changes promoted by political actors, which through alliances with librarians, conquered more space during the sixties and rec- ognized the importance of materials maintenance and documentary centers as well as the new languages necessities to attend the GLBT public, which arose a new field of studies concerning the documentation analysis.

\section{Keywords}

Homosexuality. Documentary Languages.

\section{Título}

Los termos relactivos al segmento GLBT (gays, lesbianas, bisexuales y transgéneros) en el contexto de los lenguajes documentários

\section{Resumen}

Este artículo sintetiza una monografía de conclusión de curso que investiga la importancia de las palabras relactivas a la experiencia de gays, lesbianas, bisexuales y transgéneros. La reflexión da inicio con estudios sobre la formación del lenguaje y de su importancia para la integración humana a la cultura, diferenciando el lenguaje natural del lenguaje documentário a traves de la comprensión sobre el proceso de formación de las LDs y del reconocimiento de su poder ideológico. En la secüencia, dedicase a recuperar el uso de termos relacionados a sexo y género en el decorrer de la historia y a la presentación de los sistemas organizados por Dewey y Cutter (CDD e LCSH). En este punto, es hecho un análisis sobre como esos sistemas sustentaban discursos provenientes por la autoridad científica, en primero caso, y, en el segundo, por la imposición de padrones culturales relactivos al público mayoritario y cuyas características incapacitaran esos sistemas de atender a segmentos sociales más específicos. Por fin, la reflexión destaca los cambios provocados por sujetos políticos que, aliados a los bibliotecários, ganaran espacio en los años sesenta y que reconoceran la importancia de la guardia de materiales, de centros de documentación, como la necesidad de nuevos lenguajes para atender al público GLBT, dando origen a un nuevo campo de estudios sobre el análisis de la documentación.

\section{Palabras Clave}

Homosexualidad; Lenguajes documentários. 